\title{
IMPLEMENTASI KEBIJAKAN PEMBAYARAN KAPITASI BERBASIS PEMENUHAN KOMITMEN PELAYANAN (KBKP) DI KABUPATEN JEMBER
}

\section{IMPLEMENTATION OF A CAPITATION PAYMENT POLICY BASED ON FULFILLMENT OF SERVICE COMMITMENTS (KBKP) IN JEMBER DISTRICT}

\author{
Christyana Sandra*, Yennike Tri Herawati, Ni’mal Baroya, Sulistiyani, Prehatin Trirahayu \\ Ningrum, Kurnia Ardiansyah Akbar, Andrei Ramani \\ Prodi S1 Kesehatan Masyarakat, Fakultas Kesehatan Masyarakat, Universitas Jember, Jl. Kalimantan \\ no.37 68121 Jember, Jawa Timur, Indonesia \\ *email: csandra@ unej.ac.id
}

\begin{abstract}
Capitation based on fulfillment of service commitments (KBKP) is one of the payment systems in the national health insurance program to improve effective and efficient services. The assessment through $K B K P$ indicators which included the number of contact rates, the ratio of non-specialist outpatient referrals, the ratio of prolanis participants and one additional indicator namely home visits. However, the implementation of this policy has several problems that can hinder the achievement of targets. This study uses the Implementation Research method. This research discusses various implementation problems in various contexts where data collection was carried out qualitatively (independent interview) and quantitative (secondary data analysis). Evaluation of the implementation of the KBKP since 2016 shows that there are still many challenges and obstacles so that BPJS Kesehatan issues technical instructions related to KBKP. The purpose of the preparation of the technical guidelines is to provide a joint guide to the implementation of capitation payments based on meeting service commitments in primary health care. The local government is known to be less involved in the KBKP policy; there are no policies that support the KBKP policy at the district level. Achievement of the target indicators set out in the KBKP regulations is difficult to reach by the primary health care, especially in the contact rate indicator and prolanis. Difficulty in achieving the contact rate indicator target because health workers at the primary health care did not have the time to enter data on healthy contact and ill contact in the P Care application. The KBKP policy can also improve the quality of primary health care services because the primary health care must improve infrastructure so that the 145 diagnoses can be completed.
\end{abstract}

Keyword : Capitation, KBKP Policy, Implementation Research

\begin{abstract}
Abstrak
Kapitasi berbasis pemenuhan komitmen pelayanan (KBKP) merupakan salah satu sistem pembayaran dalam program jaminan kesehatan nasional pada puskesmas untuk meningkatkan pelayanan yang efektif dan efisien sehingga mutu layanan yang diberikan dapat terjaga. Kabupaten Jember sebagai salah satu kabupaten yang menjalankan kebijakan tersebut, namun diketahui terdapat kendala dalam pelaksanaan kebijakan tersebut. Penilaian terhadap puskesmas melalui KBKP dilihat berdasarkan pencapaian indikator yang meliputi angka contact rate, rasio rujukan rawat jalan non spesialistik, rasio peserta prolanis dan 1 indikator tambahan yaitu kunjungan rumah. Namun pelaksanaan kebijakan ini terdapat beberapa permasalahan yang dapat menghambat pencapaian target. Penelitian ini menggunakan metode Riset Implementasi. Riset ini membahas berbagai masalah implementasi dalam konteks yang beragam dimana pengambilan datanya dilakukan secara kualitatif (indepth interview) dan kuantitatif (analisis data sekunder). Evaluasi pelaksanaan KBKP tahun 2016 menunjukkan masih banyaknya tantangan dan hambatan sehingga BPJS Kesehatan mengeluarkan petunjuk teknis terkait KBKP. Tujuan penyusunan petunjuk teknis tersebut adalah memberikan panduan bersama pelaksanaan pembayaran kapitasi berbasis pemenuhan komitmen pelayanan di FKTP. Pemerintah daerah diketahui kurang terlibat dalam kebijakan KBKP tersebut, tidak terdapat kebijakan yang mendukung kebijakan KBKP di tingkat
\end{abstract}


kabupaten. Pencapaian target indikator yang telah ditetapkan dalam regulasi KBKP masih sulit dicapai oleh puskesmas khususnya pada indikator contact rate, pencapaian target indicator contact rate hanya 15 puskesmas (30\%). Pencapaian indikator rujukan non spesialistik yang telah ditetapkan dalam regulasi KBKP selalu dapat dicapai oleh puskesmas $(100 \%)$, namun indikator prolanis target pencapaiannya hanya 38 puskesmas dari 50 puskesmas yang dapat mencapai (76\%). Sulitnya pencapaian target indikator contact rate karena petugas kesehatan di puskesmas tidak sempat meng-entry data kontak sehat dan kontak sakit pada aplikasi P Care. Diketahui KBKP dapat meningkatkan kepuasan peserta karena memaksa puskesmas untuk meningkatkan contact rate dengan peserta JKN dan merasa di 'spesial'kan dengan program prolanis. Kebijakan KBKP juga dapat meningkatkan mutu pelayanan puskesmas karena puskesmas harus meningkatkan sarana prasarana agar 145 diagnosis tersebut dapat diselesaikan.

Kata Kunci : Kapitasi, Kebijakan KBKP, Riset Implementasi

\section{PENDAHULUAN}

Pemerintah Indonesia dari tahun 1992 hingga kini belum mampu mewujudkan tercapainya peserta program jaminan sosial bagi seluruh penduduk Indonesia (Universal Coverage) (Kemenkes RI, 2013). Falsafah dan dasar negara Pancasila terutama sila ke 5 mengakui hak asasi warga atas kesehatan. Hal ini juga termaktub dalam UUD 1945 pasal 28H dan pasal 34, dan diatur dalam UU No 36 Tahun 2009 tentang kesehatan. UU No 36 tahun 2009 menegaskan setiap orang mempunyai hak yang sama dalam memperoleh akses atas sumber daya di bidang kesehatan dan memperoleh pelayanan kesehatan yang aman, bermutu dan terjangkau. Sebaliknya setiap orang juga mempunyai kewajiban turut serta dalam Program Jaminan Kesehatan (Peraturan Presiden RI, 2013).

Untuk mewujudkan komitmen institusi di atas, pemerintah bertanggung jawab atas pelaksanaan jaminan kesehatan masyarakat melalui Jaminan Kesehatan Nasional (JKN) sejak 1 Januari 2014. Dengan diterbitkannya UU No 24 Tahun 2011, pelaksanaan Jaminan Kesehatan Nasional dikelola oleh Badan Penyelenggara Jaminan Sosial (BPJS) bidang kesehatan, selanjutnya produk hukum lain telah diterbitkan sebagai upaya menjawab kendala yang muncul dari penyelenggara dan pengguna layanan (Kemenkes RI, 2013). Pelayanan kesehatan di era JKN diharapkan menjadi terstruktur dan berjenjang, peserta yang memerlukan pelayanan kesehatan pertamatama harus memperoleh pelayanan kesehatan pada Fasilitas Kesehatan Tingkat Pertama. Bila peserta memerlukan pelayanan kesehatan tingkat lanjutan, harus dilakukan melalui rujukan oleh fasilitas kesehatan tingkat pertama, kecuali dalam keadaan kegawatdaruratan medis (Presiden RI, 2013).
Untuk meningkatkan mutu pelayanan kesehatan di Fasilitas Kesehatan Tingkat Pertama, saat ini telah diterapkan pembayaran Kapitasi Berbasis Pemenuhan Komitmen Pelayanan (KBKP) yang telah dilaksanakan sejak tahun 2016. Penerapan pembayaran KBKP sudah mulai dilakukan sesuai dengan Peraturan Bersama Sekretaris Jenderal Kementerian Kesehatan dan Direktur Utama BPJS Kesehatan No HK.02.05/III/SK/089/2016 dan Nomor 3 Tahun 2016 tentang Petunjuk Teknis Pelaksanaan Pembayaran Kapitasi Berbasis Pemenuhan Komitmen Pelayanan pada FKTP (Maramis, Mandagi and Wowor, 2019).

Kapitasi merupakan besaran pembayaran perbulan yang dibayarkan oleh Badan Penyelenggara Jaminan Sosial (BPJS) Kesehatan kepada Fasilitas Kesehatan Tingkat Pertama yang terdaftar tanpa memperhitungkan jenis dan jumlah pelayanan kesehatan yang diberikan. Dengan demikian dapat dikatakan bahwa kapitasi yang diterima oleh setiap puskesmas berbeda. Perbedaan jumlah kapitasi yang diterima oleh puskesmas tidak hanya disebabkan oleh perbedaan jumlah pada peserta yang terdaftar dalam puskesmas tersebut, tetapi juga karena hasil kredensialing maupun rekredensialing yang dilakukan oleh BPJS Kesehatan (Dewi, Hardy and Sugianto, 2019). FKTP terdiri dari Puskesmas, praktik dokter, praktik dokter gigi, Klinik Pratama, Rumah Sakit Kelas D Pratama, dan seluruh fasilitas kesehatan yang setara. Kapitasi berbasis pemenuhan komitmen pelayanan adalah penyesuaian besaran tarif kapitasi berdasarkan hasil penilaian pencapaian indikator pelayanan kesehatan perseorangan yang disepakati bersama (BPJS Kesehatan, 2014). Hal ini berarti bahwa FKTP dapat menerima kapitasi secara maksimal ketika berhasil memenuhi 
indikator pembayaran kapitasi berbasis pemenuhan komitmen pelayanan.

Indikator yang menjadi penilaian dalam pembayaran kapitasi berbasis pemenuhan komitmen pelayanan antara lain Angka Kontak (AK), Rasio Rujukan Rawat Jalan Kasus Non Spesialistik (RRNS), Rasio Peserta Prolanis Rutin Berkunjung (RPPB), dan Rasio Kunjungan Rumah (RKR) ke FKTP (BPJS Kesehatan, 2015). Puskesmas di Jember berjumlah 50 Puskesmas. Berpegang pada keseluruhan data dan uraian di atas, serta berpegang pada hasil observasi awal dimana adanya keluhan dari puskesmas terutama dari klinik swasta terkait sulitnya mencapai indikator tersebut sehingga akan berpengaruh terhadap jumlah pembayaran kapitasi yang dibayarkan oleh BPJS Kesehatan pada puskesmas dan klinik swasta. Puskesmas yang dapat mencapai semua indikator KBKP selama tahun 2018 hanya 7 puskesmas dari 50 puskesmas. Penulis bermaksud menganalisis bagaimana pelaksanaan kebijakan tersebut di Kabupaten Jember dan permasalahan apa saja yang timbul diakibatkan kebijakan tersebut.

\section{METODE}

Penelitian ini menggunakan metode Riset Implementasi. Riset implementasi adalah bidang studi yang berkembang dengan akar dibanyak disiplin dan tradisi penelitian. Riset ini membahas berbagai masalah implementasi dalam konteks yang beragam dimana pengambilan datanya dilakukan secara kualitatif (indepth interview) dan kuantitatif (analisis data sekunder) (Peters, Tran and Adam, 2013). Data secara kualitatif didapatkan dengan melakukan wawancara mendalam terhadap kepala puskesmas di 10 puskesmas di Kabupaten Jember sedangkan data kuantitatif didapatkan dengan mengumpulkan data sekunder terkait pencapaian target KBKP di Kabupaten Jember dan khususnya di 10 puskesmas yang menjadi tempat penelitian. Dalam banyak hal, keberagaman konteks adalah kekuatan yang besar dari riset implementasi, selain memanfaatkan sumbersumber yang berbeda, membawa berbagai prespektif dan menawarkan wawasan multi sektoral namun juga menghadirkan beberapa tantangan taksonomi yang jelas dari jenis yang terkadang dihindari oleh para akademisi (Siswanto, 2019).

\section{HASIL DAN PEMBAHASAN}

Di era JKN-KIS, kualitas pelayanan kesehatan yang diberikan oleh puskesmas sangatlah penting, mengingat puskesmas merupakan ujung tombak dalam memberikan pelayanan kesehatan, sekaligus sebagai gatekeeper pelayanan kesehatan. Bila kualitas puskesmas tidak ditingkatkan, angka rujukan akan terus meningkat, sehingga bisa terjadi penumpukan pasien di rumah sakit (Peraturan Kemenkes RI dan BPJS Kesehatan nomor 2, 2017). Kapitasi berbasis pemenuhan komitmen pelayanan (KBKP) merupakan salah satu sistem pembayaran dalam program jaminan kesehatan nasional pada puskesmas untuk meningkatkan pelayanan yang efektif dan efisien sehingga mutu layanan yang diberikan dapat terjaga. Penerapan KBKP ini dinilai berdasarkan rata-rata pencapaian indikator komitmen pelayanan di puskesmas selama 3 (tiga) bulan dan menjadi dasar pembayaran kapitasi 3 (tiga) berikutnya (Widaty, 2017). Kabupaten Jember sebagai salah satu kabupaten yang menjalankan kebijakan tersebut, namun diketahui terdapat kendala dalam pelaksanaan kebijakan tersebut.

Penilaian terhadap puskesmas melalui KBKP dilihat berdasarkan pencapaian indikator yang meliputi beberapa aspek. Pertama adalah angka kontak yang merupakan indikator untuk mengetahui tingkat aksesibilitas dan pemanfaatan pelayanan primer di puskesmas oleh peserta berdasarkan jumlah peserta JKN (per nomor identitas peserta). Indikator kedua adalah rasio rujukan rawat jalan non spesialistik untuk mengetahui kualitas pelayanan di puskesmas, sehingga sistem rujukan terselenggara sesuai indikasi medis dan kompetensi puskesmas. Selanjutnya yang menjadi indikator ketiga adalah Rasio Peserta Prolanis (Program Pengelolaan Penyakit Kronis) rutin berkunjung ke puskesmas, yang merupakan indikator untuk mengetahui kesinambungan pelayanan penyakit kronis yang disepakati oleh BPJS Kesehatan dan puskesmas terhadap peserta prolanis. Indikator tambahan yaitu kunjungan rumah. Bagi puskesmas yang sudah memenuhi persyaratan untuk menerapkan KBKP namun dalam jangka waktu paling lama 3 (tiga) bulan sejak kebijakan ditetapkan namun belum menjalankan penerapan KBKP, pembayaran kapitasi diberikan sebesar 90\% dari norma kapitasi (Maramis, Mandagi and Wowor, 2019). 
Penelitian ini menjawab sejumlah pertanyaan dalam tujuan yang terkait dengan pelaksanaan KBKP di Kabupaten Jember khususnya di 10 puskesmas.

\section{Isi dan Tujuan Kebijakan Pembiayaan Kapitasi Berbasis Komitmen Pelayanan (KBKP).}

Berbagai jenis pengukuran, standar dan upaya untuk meningkatkan mutu pelayanan telah tersedia dan terus berkembang. Salah satunya adalah dengan metode pembayaran berbasis komitmen pelayanan, dimana metode ini merupakan salah satu konsep strategis yang paling banyak dibahas, bahkan berbagai kalangan di Amerika sejak tahun 2003 telah mendorong agar pembayaran berbasis komitmen pelayanan atau pay for performance menjadi prioritas utama nasional dan program asuransi medicare. Dalam rangka meningkatkan mutu pelayanan kesehatan Fasilitas Kesehatan Tingkat Pertama pada penyelenggaraan Program Jaminan Kesehatan Nasional salah satunya dilakukan penerapan pembayaran kapitasi berbasis pemenuhan komitmen pelayanan. Pembayaran kapitasi berbasis pemenuhan komitmen pelayanan pada FKTP telah mulai dilaksanakan pada tahun 2016 (Peraturan Kemenkes RI dan BPJS Kesehatan nomor 2, 2017).

Berdasarkan hasil evaluasi pelaksanaan kapitasi berbasis pemenuhan komitmen pelayanan tahun 2016, terdapat adanya tantangan dan masukan yang didapatkan untuk perbaikan pelaksanaan kapitasi berbasis pemenuhan komitmen pelayanan. Sehubungan dengan hal tersebut, dilakukan pengembangan pelaksanaan kapitasi berbasis pemenuhan komitmen pelayanan tahun 2017 yang akan diberlakukan bagi seluruh puskesmas, klinik pratama, praktik mandiri dokter, dan rumah sakit kelas D pratama, sehingga pelaksanaan dan penerapan kapitasi berbasis pemenuhan komitmen pelayanan di FKTP berjalan efektif dan efisien (Peraturan Kemenkes RI dan BPJS Kesehatan nomor 2, 2017).

Tujuan penyusunan Petunjuk Teknis Pelaksanaan Pembayaran Kapitasi Berbasis Pemenuhan Komitmen Pelayanan pada Fasilitas Kesehatan Tingkat Pertama adalah :

1. menjelaskan perubahan dalam persiapan, pelaksanaan, penilaian hingga monitoring dan evaluasi pembayaran kapitasi berbasis pemenuhan komitmen pelayanan di FKTP.
2. Memberikan panduan bersama bagi seluruh pihak terkait dalam pelaksanaan pembayaran kapitasi berbasis pemenuhan komitmen pelayanan di FKTP.

\section{Ketersediaan Kebijakan Pembiayaan Kapitasi Berbasis Komitmen Pelayanan (KBKP) di Tingkat Kabupaten}

Pelaksanaan KBKP di kabupaten mengacu pada Peraturan Bersama Sekretaris Jenderal Kementerian Kesehatan Republik Indonesia dan Direktur Utama Badan Penyelenggara Jaminan Sosial Kesehatan Nomor HK.01.08/III/980/2017 Tahun 2017 Nomor 2 Tahun 2017 Tentang Petunjuk Teknis Pelaksanaan Pembayaran Kapitasi Berbasis Pemenuhan Komitmen Pelayanan Pada Fasilitas Kesehatan Tingkat Pertama (Peraturan Kemenkes RI dan BPJS Kesehatan nomor 2, 2017). Namun saat diwawancara, seluruh informan mengetahui keberadaan regulasi tersebut namun belum membaca dan memahami kecuali yang terkait dengan indikator pemenuhan KBKP seperti yang tertulis dalam kutipan berikut :

"Ohhh kalo UU nya ndak apal aku dan peraturannya di BPJS juga ada tapi yaitu ndak apal..." (TW, 55 tahun)

"Itu ada aku lupa dijelaskan waktu rapat tiap bulan dengan BPJS selalu ditampilkan" (HS, 46 tahun)

Seluruh puskesmas berkomitmen melaksanakan kebijakan tersebut demi mendapatkan kapitasi secara penuh walau terdapat berbagai macam hambatan. Pemerintah daerah diketahui kurang terlibat dalam kebijakan KBKP tersebut, tidak terdapat kebijakan yang mendukung kebijakan KBKP di tingkat kabupaten. Hal ini dimungkinkan disebabkan karena tidak ada komunikasi yang baik antara pemerintah daerah dan BPJS Kesehatan. Hal tersebut dikutip dalam pernyataan berikut :

"Pemerintah daerah tidak pernah melakukan monitoring dan evaluasi terkait pelaksanaan KBKP. Yang mengevaluasi itu BPJS karena memang hal itu kebutuhan BPJS untuk membayar kapitasi. Dinas Kesehatan tidak pernah memonitor, kita hanya diajak diskusi saja tiap 3 bulan sekali" (IT, 42 tahun). 
"Jadi monev ini selalu dilaksanakan tiap 3 bulan dengan pihak bpjs untuk mengetahui kendala kendala pada tiap indikator dan indikator mana yang belum tercapai" (HP, 34 tahun).

Pernyataan tersebut mengkonfirmasi bahwa pemerintah daerah juga tidak melakukan monitoring dan evaluasi terkait pelaksanaan kebijakan KBKP. Menurut Peraturan Pemerintah Nomor 39 Tahun 2006, disebutkan bahwa monitoring merupakan suatu kegiatan mengamati secara seksama suatu keadaan atau kondisi, termasuk juga perilaku atau kegiatan tertentu dengan tujuan agar semua data masukan atau informasi yang diperoleh dari hasil pengamatan tersebut dapat menjadi landasan dalam mengambil keputusan tindakan selanjutnya yang diperlukan (Peraturan Presiden RI, 2006). Sedangkan menurut Mustofa, evaluasi adalah proses menentukan nilai atau pentingnya suatu kegiatan, kebijakan atau program (Mustofa, 2012).

\section{Pelaksanaan Kebijakan Pembiayaan Kapitasi Berbasis Komitmen Pelayanan (KBKP) di Kabupaten Jember}

Hasil studi evaluasi penerapan kapitasi berbasis pemenuhan komitmen di Kabupaten Jember pada bulan Juli-September 2018 menunjukkan bahwa secara umum puskesmas telah berkomitmen dalam mencapai target indikator KBKP namun dalam pelaksanaannya masih terjadi berbagai hambatan. Pencapaian target indikator yang telah ditetapkan dalam regulasi KBKP masih sulit dicapai oleh puskesmas khususnya pada indikator contact rate, pencapaian target indicator contact rate hanya 15 puskesmas (30\%). Pencapaian indikator rujukan non spesialistik yang telah ditetapkan dalam regulasi KBKP selalu dapat dicapai oleh puskesmas (100\%), namun indikator prolanis target pencapaiannya hanya 38 puskesmas dari 50 puskesmas yang dapat mencapai $(76 \%)$.

Sulitnya pencapaian target indikator contact rate karena petugas kesehatan di puskesmas tidak sempat meng-entry data kontak sehat dan kontak sakit pada aplikasi $\mathrm{P}$ Care. Program yang ada di puskesmas sangat banyak terutama program kesehatan masyarakat sedangkan staf ada sangat terbatas, kesibukan dengan penyelesaian programprogram tersebut menyebabkan staf merasa tidak ada waktu untuk memasukkan data kontak sehat dan kontak sakit ke aplikasi P Care. Hal tersebut dikutip dari pernyataan berikut :

"Yang susah dicapai itu angka kontak bu, karena kelemahan di puskesmas ini kegiatan mencatat nya yang kurang. Trus males memasukkan ke P Care bisa karena lupa password, $P$ Care down, atau memang waktunya gak ada. Kegiatan di puskesmas kan tidak hanya UKP tapi UKM itu yang menyita waktu" (AF, 38 tahun).

"Nah dari tiga indikator itu kami sudah dua yang mencapai target artinya zona kami aman. Yang pertama yang terkait dengan kontak rate itu yang kami belum mencapai target. Itu karena perhitungannya memang banyak ternyata ya kami sudah targetkan sudah kami hitung kayaknya masuk tapi ternyata tidak masuk berarti dan itupun mungkin kurang sedikit-sedikit karena kami mencapai $140 \%$ yang seharusnya $150 \%$ jadi ya itu seharusnya tinggal sedikit malah tidak masuk belum pernah ke aman. Ya mungkin inilah kami dalam proses untuk penguat itu" (ERP, 58 tahun)

Pernyataan tersebut mengkonfirmasi bahwa kegiatan entry data menjadi beban tambahan bagi petugas puskesmas. Beberapa puskesmas membuat kebijakan secara mandiri yang diberlakukan di puskesmasnya masingmasing agar hambatan peng-entry-an data kontak sehat dan kontak sakit ke aplikasi P Care dapat diatasi. Salah satu kebijakan yang diterapkan oleh puskesmas adalah mewajibkan setiap staf yang ada di puskesmas untuk setiap hari meng-entry data ke aplikasi P Care secara bergantian. Hal tersebut terbukti dapat meningkatkan target pencapaian contact rate di puskesmas tersebut. Hal tersebut termaktub dalam pernyataan berikut :

"Sebenarnya tidak berat ya bu. Setelah rata semua staf mempunyai kewajiban memasukkan data ke P Care ternyata hanya butuh waktu 10 menit dalam 1 bulan. Jadi data itu direkap dulu, staf harus mencatat di buku masing-masing. Kemudian tiap 1 bulan sekali wajib duduk di depan $P$ Care 10 menit untuk memasukkan data tadi ke P Care" (AF-IU, 38 tahun). 
Keluhan tersebut berbeda dengan yang terjadi di klinik swasta, pencapaian ke 3 indikator plus 1 indikator tambahan selalu tercapai. Indikator kunjungan rumah justru dapat membantu indicator contact rate karena dapat menaikkan angka kunjungan sehat yang dilaksanakan oleh puskesmas.

\section{Efektifitas Kebijakan Pembiayaan Kapitasi Berbasis Komitmen Pelayanan (KBKP) di Kabupaten Jember}

Kebijakan KBKP jika dianalisis melalui pencapaian target indikator maka dapat disimpulkan kebijakan tersebut belum dapat dikatakan efektif dapat dilaksanakan dengan baik oleh puskesmas. Namun kebijakan KBKP ini diketahui dapat meningkatkan kepuasan peserta karena memaksa puskesmas untuk meningkatkan contact rate dengan peserta JKN dan merasa di 'spesial'kan dengan program prolanis. Hal tersebut termaktub dalam pernyataan berikut :

"Jelas dapat meningkatkan kepuasan peserta apalagi prolanis, karena pasien merasa dikhususkan. Jadi pasien punya fasilitas khusus salah satunya pemeriksaan lengkap berkala yang difasilitasi BPJS. Ada kegiatan refreshing juga untuk prolanis. Untuk angka kontak juga begitu, karena kebijakan ini memaksa puskesmas untuk meningkatkan angka kontak dengan peserta" (EL-IU, 32 tahun).

Kebijakan KBKP juga dapat meningkatkan mutu pelayanan puskesmas dan meningkatkan kepuasan pasien karena puskesmas harus meningkatkan sarana prasarana agar 145 diagnosis tersebut dapat diselesaikan (Ulandari, S dan Yudawati, 2019).

\section{KESIMPULAN DAN SARAN}

\section{Kesimpulan}

Berdasarkan hasil penelitian, diketahui bahwa dalam pelaksanaan kebijakan terkait KBKP tersebut sebagian besar puskesmas di Kabupaten Jember tidak dapat mencapai target indikator contact rate. Kedua indikator lainnya (rasio rujukan dan prolanis) sebagian besar puskesmas dapat mencapai target tersebut. Terdapat beberapa hambatan dalam pelaksanaan kebijakan KBKP di Kabupaten Jember. Salah satu hambatan adalah tidak adanya keterlibatan pemerintah daerah terkait pelaksanaan kebijakan KBKP ini sehingga pemerintah daerah sama sekali tidak ada komunikasi dan koordinasi dengan BPJS Kesehatan.

\section{Saran}

Rekomendasi yang dapat diberikan yaitu harus ada keterlibatan pemerintah dalam pelaksanaan kebijakan KBKP sehingga terbangun komunikasi dan koordinasi yang baik antar pihak-pihak yang terkait yaitu pemerintah daerah, Dinas Kesehatan Kabupaten Jember dan BPJS Kesehatan, Pemerintah daerah bekerja sama dengan dinas kesehatan dan BPJS perlu menyusun kebijakan secara menyeluruh di seluruh puskesmas terkait upaya pencapaian target contact rate yang telah terbukti efektif dapat meningkatkan target pencapaian contact rate. Dinas Kesehatan Kabupaten Jember dapat melakukan pembinaan dan pengawasan secara berkala agar kebijakan tersebut dapat terlaksana dan memastikan seluruh puskesmas di Kabupaten Jember dapat mencapai seluruh target indikator.

\section{DAFTAR PUSTAKA}

1] BPJS Kesehatan (2014) 'INA CBGs Membuat Biaya Kesehatan Lebih Efektif Edisi VIII', BPJS Kesehatan.

2] BPJS Kesehatan (2015) 'Peraturan Badan Penyelenggara Jaminan Sosial Kesehatan Nomor 2 Tahun 2015 tentang norma penetapan besaran kapitasi dan pembayaran kapitasi berbasis pemenuhan komitmen pelayanan pada fasilitas kesehatan tingkat pertama'.

3] Dewi, N. M. ., Hardy, I. P. D. . and Sugianto, M. . (2019) 'GAMBARAN PENCAPAIAN INDIKATOR KAPITASI BERBASIS', Prosiding Sintesa, pp. 161172. doi: http://dx.doi.org/10.36002/snts.v0i0.832.

4] Kemenkes RI (2013) Panduan Sosialisasi $J K N$. Jakarta: Kemenkes RI. doi: 10.1017/CBO9781107415324.004.

5] Maramis, J. V. F., Mandagi, C. K. F. and Wowor, R. (2019) 'Analisis Pencapaian Indikator Kapitasi Berbasis Komitmen (Kbk) Terhadap Pembayaran Dana Kapitasi Di Puskesmas Wawonasa Kota Manado', Kesmas, 7(4). Available at: http://www.ejournalhealth.com/index.php/ kesmas/article/view/892. 
6] Mustofa, M. L. (2012) Monitoring dan Evaluasi. UIN-Maliki Press.

7] Peraturan Kemenkes RI dan BPJS Kesehatan nomor 2 (2017) 'Badan Penyelenggara Jaminan Sosial Kesehatan Nomor Hk.01.08/Lii/980/2017 Tahun 2017 Nomor 2 Tahun 2017 Tentang Petunjuk Teknis Pelaksanaan Pembayaran Kapitasi Berbasis Pemenuhan Komitmen Pelayanan Pada Fasilitas Kesehatan Tingkat Pertama'.

8] Peters, D. H., Tran, N. T. and Adam, T. (2013) Implementation Research in Health: A Practical Guide, WHO. Edited by W. H. Organization.

9] Presiden, P. (2006) PERATURAN PEMERINTAH REPUBLIK INDONESIA NOMOR 39 TAHUN 2006 TENTANG TATA CARA PENGENDALIAN DAN EVALUASI PELAKSANAAN RENCANA PEMBANGUNAN. Jakarta: Presiden RI.
10] Presiden RI (2013) 'Peraturan presiden no 12 tahun 2013 tentang Jaminan Kesehatan'. Jakarta: Presiden RI.

11] Siswanto (2019) 'Metodologi Riset untuk Mengawal Kebijakan', Buletin Penelitian Sistem Kesehatan, 22(2), pp. 137-145. doi: 10.22435/hsr.v22i2.2050.

12] Ulandari, S dan Yudawati, S. (2019) 'ANALISIS KUALITAS PELAYANAN, SARANA PRASARANA DAN LINGKUNGAN TERHADAP KEPUASAN PASIEN', Ilmiah Ilmu Kesehatan, 7(2), pp. 39-53.

13] Widaty, D. (2017) 'Analisis Pemenuhan Indikator Pembayaran Kapitasi pada Fasilitas Kesehatan Tingkat Pertama di Surabaya', Jurnal Administrasi Kesehatan Indonesia, 5(2), p. 111. doi: 10.20473/jaki.v5i2.2017.111-116. 